\title{
PENGARUH BUKAAN SUDU PENGARAH TERHADAP KERUGIAN HEAD DAN PERFORMANSI TURBIN FRANCIS VERTIKAL
}

\author{
Mansur P. Siregar ${ }^{1}$, A. Halim Nasution ${ }^{2}$, Syahril Gultom ${ }^{3}$, A. Husein Siregar ${ }^{4}$, Mahadi ${ }^{5}$ \\ 1.2,3,4,5 Departemen Teknik Mesin, Fakultas Teknik, Universitas Sumatera Utara \\ E-mail : mansursiregar8@yahoo.com
}

\begin{abstract}
ABSTRAK
Pembangkit Listrik Tenaga Air masih menjadi tumpuan utama pembangkitan energi listrik di dunia khususnya Indonesia.Data pada tahun 2006 menunjukan bahwa hampir 20\% kebutuhan listrik dunia berasal dari PLTA atau sekitar $88 \%$ sumber energi terbarukan berasal dari pemanfaatan tenaga air. Ján Andrej Segner mengembangkan turbin air reaksi pada pertengahan tahun 1700. Turbin ini mempunyai sumbu horizontal dan merupakan awal mula dari turbin air modern. Hingga pada tahun 1849, James B. Francis meningkatkan efisiensi turbin reaksi hingga lebih dari 90\%. Dia memberikan test yang memuaskan dan mengembangkan metode keteknikan untuk desain turbin air. Turbin Francis dinamakan sesuai dengan namanya, yang merupakan turbin air modern pertama dengan efisiensi lebih dari $90 \%$.Oleh karena itu dalam pengoperasiannya Turbin Francis harus optimal. Adapun tujuan penelitian ini yaitu membahas pengaruh bukaan sudu pengarah terhadap kerugian head dan performansi Turbin Francis. Kerugian head dihitung menggunakan rumus dan besarnya kerugian head pada instalasi turbin dianalisa dengan menggunakan software Pipe Flow Expert untuk mendapatkan ralat perhitungan. Kemudian dihitung daya dan efisiensi turbin Francis Besarnya nilai kerugian head akan semakin besar seiring dengan bukaan sudu pengarah. Kerugian head terkecil yaitu 0,229 $\mathrm{m}$ kemudian akan terus naik hingga bukaan maksimum $195 \mathrm{~mm}$ besarnya kerugian head mencapai 20,1375 m. Efisiensi turbin Francis akan terus naik seiring bukaan sudu pengarah akan tetapi pada bukaan $195 \mathrm{~mm}$ efisiensi turun pada titik 90,4\%. Sehingga didapat bahwa bukaan sudu pengarah yang menghasilkan efisiensi maksimum yaitu pada bukaan $160,5 \mathrm{~mm}$ yaitu sebesar $98 \%$.
\end{abstract}

Kata kunci : Kerugian Head, Pipe Flow Expert, Daya, Efisiensi

\section{PENDAHULUAN}

Sumber daya energi terbarukan akan menawarkan pilihan yang lebih bersih untuk menggantikan bahan bakar fosil. Sumber daya tersebut lebih sedikit atau bahkan tidak mencemari atau pun menghasilkan gas rumah kaca, dan sumber daya tersebut akan tetap tersedia.

Energi air adalah salah satu sumber energi dengan daya terbesar yang saat ini digunakan di belahan dunia. Keadaan ini menyebabkan pembangunan pusat tenaga air sebagai penghasil energi alternatif menjadi pilihan yang menarik, PLTA bersifat ramah lingkungan dan memiliki dampak yang sangat ramah lingkungan dibandingkan dengan pembangkit lain.

PLTA tergolong pembangkit yang tidak menghasilkan limbah secara langsung. Kelebihan lain adalah level emisi gas rumah kaca karbondioksida dari PLTA yang sangat rendah dibandingkan dengan pembangkit yang menggunakan bahan bakar dari fosil.

Dengan besarnya keuntungan tersebut, banyak negara membangun PLTA untuk memenuhi kebutuhan listrik mereka. Pada pengoperasian sebuah PLTA digunakan berbagai variabel agar PLTA tersebut dapat beroperasi optimal. Diantara variabel tersebut diantaranya adalah pengaturan bukaan sudu pengarah yang akan mempengaruhi besarnya nilai kerugian head dan performansinya. Oleh sebab itu sudu pengarah sangat 
penting diatur sedemikian rupa agar turbin Francis dapat bekerja pada efisisiensi yang terbaik.

\section{TINJAUAN PUSTAKA \\ Persamaan Mekanika Fluida \\ Massa Jenis}

Massa jenis merupakan perbandingan massa per volume fluida pada tekanan dan temperatur tertentu[1] . Massa jenis disimbolkan dengan $\rho$ (rho) dengan persamaan:

\section{Debit Air}

$$
\rho=\frac{m}{v} \ldots \ldots . . . . .[1]
$$

Debit dihitung dengan persamaan:

$$
\mathrm{Q}=\mathrm{V} . \mathrm{A} \ldots \ldots . .[2]
$$

\section{Persamaan Kontinuitas}

Jika sebuah fluida tak termampatkan mengalir sepanjang pipa, massa fluida yang melewati tiap pipa itu dinyatakan:

$$
A_{1} V_{1}=A_{2} V_{2}
$$

Dimana:

$\mathrm{A}_{1}=$ Luas Penampang 1

$\mathrm{V}_{1}=$ Kecepatan Aliran Fluida 1

$\mathrm{A}_{2}=$ Luas Penampang 2

$\mathrm{V}_{2}=$ Kecepatan Aliran Fluida 2

\section{Persamaan Bernoulli}

Persamaan bernoulli menyatakan bahwa pada fluida tak termampatkan (incompressible) yang mengalir sepanjang pipa maka total energinya sama pada saaat partikel fluida mengalir dari satu titik ke titik lainnya [1]. Dan dirumuskan:

$$
\frac{\mathrm{p}_{1}}{\gamma}+\frac{\mathrm{V}_{1}^{2}}{2 \mathrm{~g}}+\mathrm{z}_{1}=\frac{\mathrm{p}_{2}}{\gamma}+\frac{\mathrm{V}_{2}^{2}}{2 \mathrm{~g}}+\mathrm{z}_{2}
$$

Dimana:

$\mathrm{P}=$ Tekanan fluida $(\mathrm{Pa})$

$\gamma=$ kerapatan air $\left(\mathrm{N} / \mathrm{m}^{3}\right)$

$\mathrm{V}=$ kecepatan Aliran Air Fluida (m/s)

$\mathrm{z}=$ Ketinggian head $(\mathrm{m})$

$\mathrm{g}=$ kecepatan gravitasi $\left(\mathrm{m} / \mathrm{s}^{2}\right)$

\section{Kerugian Head Mayor}

Kerugian head ini terjadi akibat adanya gesekan antara dinding pipa dengan fluida yang mengalir di dalamnya [2]. Persamaan umumnya ada 2 yaitu DarcyWeisbach dan persamaan Hazen-Williams.

Persamaan Darcy-Weisbach:

$$
\mathrm{h}_{\mathrm{f}}=\mathrm{f} \frac{L}{D} \cdot \frac{v^{2}}{2 g} \ldots \ldots[4]
$$

Dimana:

$\mathrm{h}_{\mathrm{f}}=$ kerugian head mayor $(\mathrm{m})$

$\mathrm{L}=$ panjang pipa $(\mathrm{m})$

$\mathrm{D}=$ diameter dalam dari pipa $(\mathrm{m})$

$\mathrm{v}=$ kecepatan aliran fluida $(\mathrm{m} / \mathrm{s})$

$\mathrm{g}=$ percepatan gravitasi $\left(\mathrm{m} / \mathrm{s}^{2}\right)$

$\mathrm{f}=$ koefisien Moody. 
Persamaan Hazen-Williams

$$
\mathrm{h}_{\mathrm{f}}=\frac{10,666 Q^{1,85}}{C^{1,85} d^{4,85}} \mathrm{~L}
$$

$\mathrm{h}_{\mathrm{f}}=$ kerugian gesekan dalam pipa $(\mathrm{m})$

$\mathrm{Q}=$ laju aliran dalam pipa $\left(\mathrm{m}^{3} / \mathrm{s}\right)$

$\mathrm{L}=$ panjang pipa $(\mathrm{m})$

$\mathrm{C}=$ koefisien kekasaran pipa Hazen - Williams

$\mathrm{d}=$ diameter pipa $(\mathrm{m})$

\section{Kerugian Head Minor}

Kerugian ini terjadi karena kelengkapan pipa seperti belokan, siku, sambungan, katup dan sebagainya yang disebut dengan kerugian head minor[4]. Kerugian head minor dirumuskan:

$$
h_{m}=\Sigma \text { n.k } \cdot \frac{V^{2}}{2 g} \ldots \ldots \ldots . .[6]
$$

dimana:

$\mathrm{n}=$ jumlah kelengkapan pipa

$\mathrm{k}=$ koefisien kerugian minor

$\mathrm{v}=$ kecepatan aliran fluida dalam pipa $(\mathrm{m} / \mathrm{s})$

$\mathrm{g}=$ percepatan gravitasi $\left(\mathrm{m} / \mathrm{s}^{2}\right)$

\section{Turbin Francis}

Turbin Francis paling banyak digunakan di Indonesia. Teknik mengkonversikan energi potensial menjadi energi mekanik pada roda turbin air dilakukan melalui proses reaksi sehingga turbin francis sering disebut turbin reaksi. [7]

\section{Head efektif}

Yang dimaksud dengan head efektif adalah tinggi jatuh air aktual dikurangi total kerugian head (head losses), dengan persamaan berikut:

$$
\mathrm{H}_{\mathrm{eff}}=\mathrm{H}_{\max }-\Sigma \mathrm{H}_{\mathrm{L}} \ldots . .[8]
$$

\section{Daya Air (WHP), Daya turbin (BHP) dan Efisiensi}

Adapun perumusannya yaitu:

$$
\begin{gathered}
\mathrm{WHP}=\mathrm{Q} \cdot \rho \cdot \mathrm{g} \cdot \mathrm{H}_{\mathrm{effektif} \ldots . .[9]} \\
P g=\rho \cdot \mathrm{g} \cdot Q \cdot H \cdot \eta G \cdot \eta_{\mathrm{turbin}} . .[9] \\
B H P=\frac{P G}{\eta G} \ldots \ldots . .[9] \\
\eta_{\mathrm{turbin}}=\frac{B H P}{W H P} \ldots[10]
\end{gathered}
$$

Dimana:

$\mathrm{Q}=$ Debit air $\left(\mathrm{m}^{3} / \mathrm{s}\right)$

$\mathrm{g}=$ Gaya gravitasi $\left(\mathrm{m} / \mathrm{s}^{2}\right)$

$\mathrm{H}=$ Head (m)

$\mathrm{P}_{\mathrm{g}}=$ Daya generator (watt)

$\rho=$ massa jenis air $\left(/ \mathrm{m}^{3}\right)$

$\eta G=$ Efisiensi generator $(\%)$

$\eta_{\text {turbin }}=$ Efisiensi turbin $(\%)$

WHP = Daya air (watt)

$B H P=$ Daya turbin (watt)

\section{METODOLOGI PENELITIAN}




\section{Metode pengumpulan data}

Data yang dipergunakan dalam pengujian ini meliputi :

a. Data primer, merupakan data yang diperoleh dari pengujian di PLTA Siguragura Unit 3 PT. Inalum (Persero)

b. Data sekunder, merupakan data yang bersumber dari pustaka-pustaka yang mendukung penelitian.

\section{Metode Pengolahan Data}

Metode yang digunakan dalam penelitian yaitu metode eksperimental dan analisis. Data diolah menggunakan rumus yang ada dan dihitung menggunakan Microsoft Excel dan program Pipe Flow Expert, kemudian hasil dari perhitungan disajikan dalam bentuk tabulasi dan grafik.
Alat Pembacaan Data
a. Guide Vane Meter
b. Power Meter
c. Precise Mercury Termometer
d. Ultrasonic Flowmeter
e. Local Control Room (LCR)

\section{Instalasi Penelitian}

Adapun instalasi PLTA Siguragura dapat dilihat di gambar 1 berikut ini:

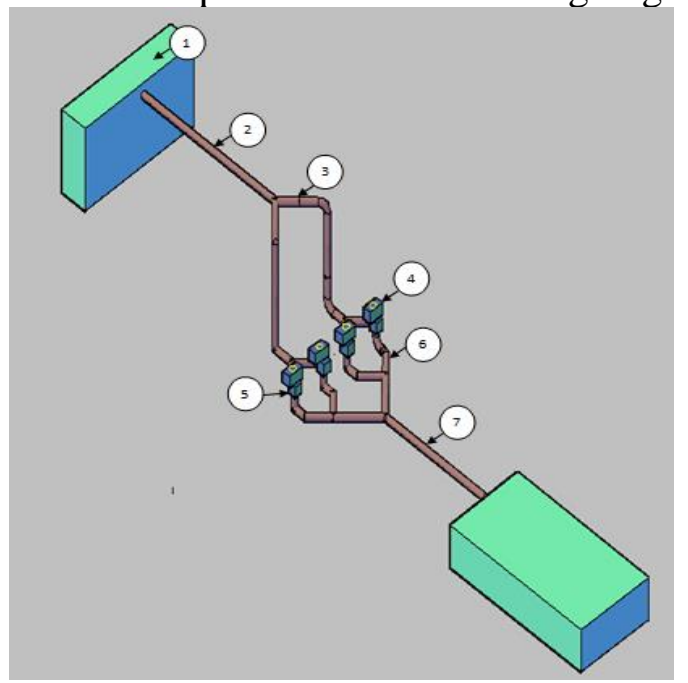

Gambar 1. Instalasi PLTA Siguragura

Keterangan:

1. Bendungan Siguragura

2. Head Race Tunnel

3. Penstock

4. Generator

5. Turbin Francis

6. Draft Tube

7. Tailrace

\section{Prosedur Penelitian}

Adapun Prosedur pada penelitian ini yaitu 
1. On The Job Training "efficiency test" unit 3 Siguragura"

2. Survey kembali Lapangan di PLTA siguragura unit 3

3. Pengambilan data

4. Dihitung kerugian head menggunakan rumus di Ms. Excel

5. Jaringan pipa disimulasikan menggunakan program Pipe Flow Expert v.12

6. Dianalisa data untuk memperoleh ralat kerugian head

7. Dihitung daya air $(W H P)$ dan daya Turbin $(B H P)$

8. Dihitung efisiensi Turbin Francis Vertikal Unit 3 Siguragura.

\section{ANALISA \& PEMBAHASAN}

Hubungan Antara Bukaan Sudu Pengarah( Guide Vane Opening/ GVO) dengan Debit Air Masuk Turbin

Pada saat pengujian dilakukan pembukaan Sudu Pengarah sebesar $195 \mathrm{~mm}$; $160,5 \mathrm{~mm} ; 150 \mathrm{~mm} ; 143 \mathrm{~mm} ; 136 \mathrm{~mm} ; 129,5 \mathrm{~mm} ; 102 \mathrm{~mm} ; 78 \mathrm{~mm}$ dan $19,5 \mathrm{~mm}$. Bukaan sudu pengarah dalam data akan disimbolkan dengan GVO (Guide Vane Opening).

Adapun pengaruh bukaan sudu pengarah terhadap debit air masuk turbin dapat dilihat pada gambar 2.

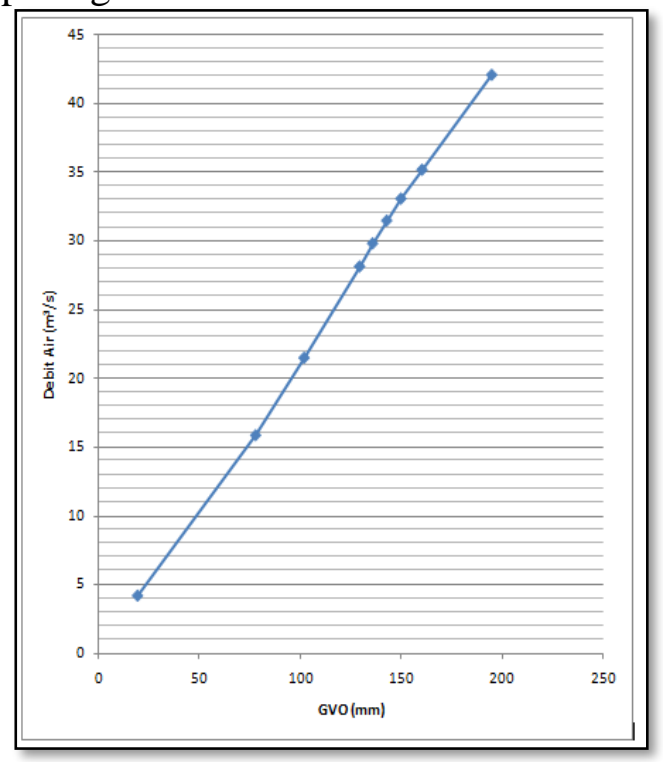

Gambar 2. Grafik Hubungan Bukaan Sudu Pengarah terhadap Debit Air Masuk Turbin

Dari gambar 2 dapat lihat bahwa semakin besar bukaan sudu pengarah maka debit air masuk turbin akan semakin besar pula hal ini dekarenakan katup bukaan air akan semakin besar untuk memasuki turbin. Pada bukaan terkecil yaitu 19,5 mm debit air masuk turbin yaitu $4,251 \mathrm{~m}^{3} / \mathrm{s}$ dan akan terus naik hingga bukaan $195 \mathrm{~mm}$ yaitu sebesar $42,14 \mathrm{~m}^{3} / \mathrm{s}$.

\section{Pengaruh Bukaan Sudu Pengarah Terhadap Kerugian Head dan Head Efektif}

Semakin besarnya kerugian head yang terdapat pada turbin ini diakibatkan oleh semakin besarnya debit air yang masuk turbin dan semakin cepatnya aliran air di dalam turbin. Adapun pengaruh bukaan sudu pengarah terhadap kerugian head dapat dilihat pada gambar 3 berikut. 


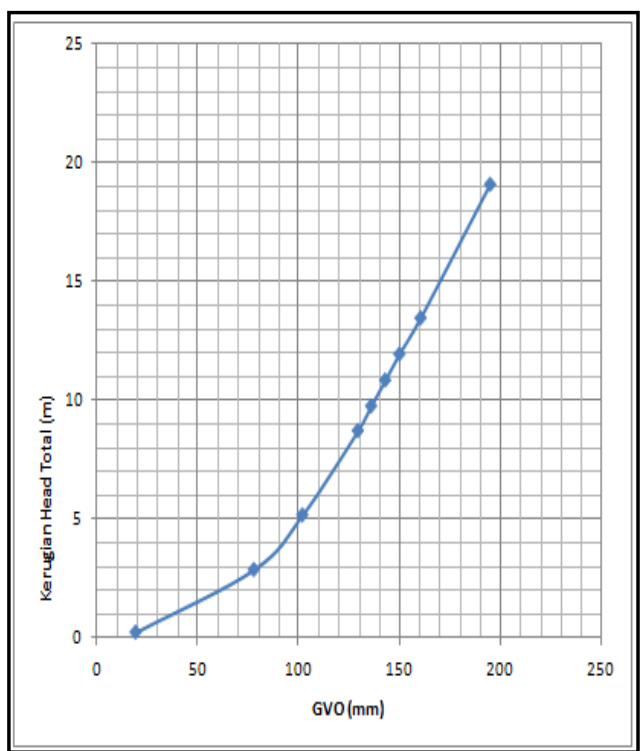

Gambar 3. Grafik hubungan Bukaan Sudu Pengarah terhadap Kerugian Head Total

Dari gambar 3 dapat dilihat bahwa semakin besar bukaan sudu pengarah maka akan bertambah juga besarnya kerugian head. Pada bukaan 19,5 mm kerugian head sebesar 0,229 $\mathrm{m}$ dan terus naik seiring bukaan sudu pengarah hingga pada bukaan 195 $\mathrm{mm}$ kerugian head sangat besar yaitu mencapai 20, $1375 \mathrm{~m}$.

Semakin besar bukaan sudu pengarah maka head efektif yang bekerja pada Turbin Francis akan semakin kecil. Hal ini dikarenakan nilai kerugian head yang semakin besar perbukaan sudu pengarah. Hubungan bukaan sudu pengarah dengan head efektif dapat dilihat pada gambar 4.

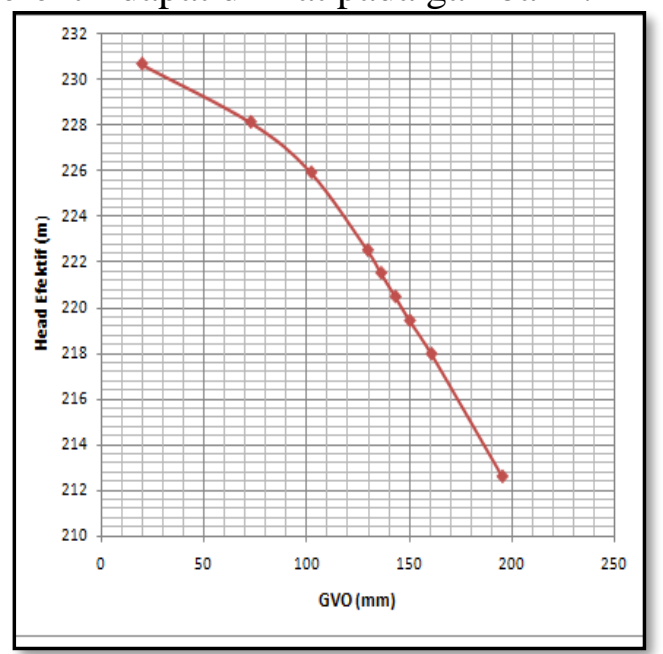

Gambar 4. Grafik hubungan Bukaan Sudu Pengarah terhadap Head Efektif

Dari gambar 4 diatas terlihat bahwa semakin besar bukaan sudu pengarah maka head efektif yang bekerja pada turbin akan semakin kecil. Head efektif terkecil yaitu pada bukaan $195 \mathrm{~mm}$ yaitu sebesar 210,76 m dan terbesar paada bukaan 19,5 mm yaitu sebesar 230,67 m. Hal ini terjadi karena besarnya kerugian head yang semakin meningkat perbukaan sudu pengarah seperti dijelaskan sebelumnya.

\section{Analisa Kerugian Head Menggunakan Program Pipe Flow Expert v.12.1}

Untuk medapatkan persen ralat penghitungan kerugian head digunakan program Pipe Flow Expert v.12.1. Jaringan Pipa pada program Pipe Flow Expert dapat dilihat pada gambar 5. 


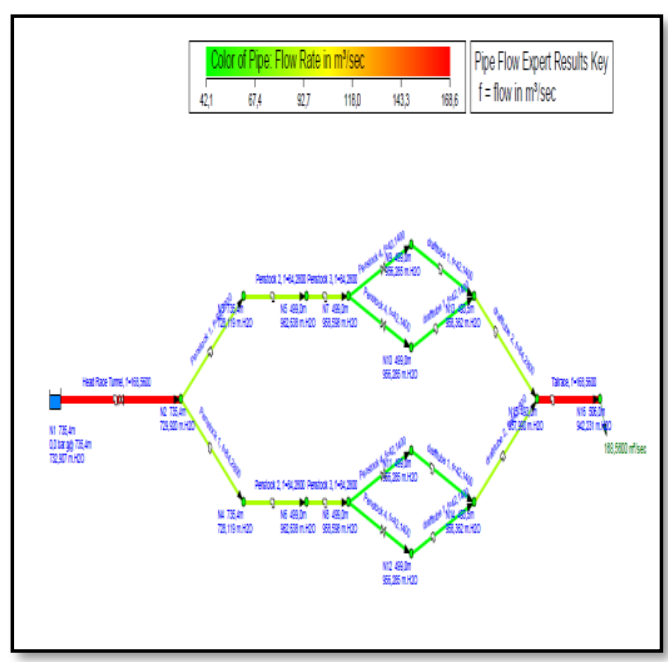

Gambar 5. Jaringan Pipa pada Program Pipe Flow Expert

Dengan menggunakan program Pipe Flow Expert dihitung besarnya kerugian head pada tiap-tiap bukaan sudu pengarah mulai dari bukaan $195 \mathrm{~mm}$ sampai 19,5 mm. Perbandingan hitungan rumus di Ms. Excel dan proran Pipe Flow Expert dapat dilihat pada gambar 6 berikut.

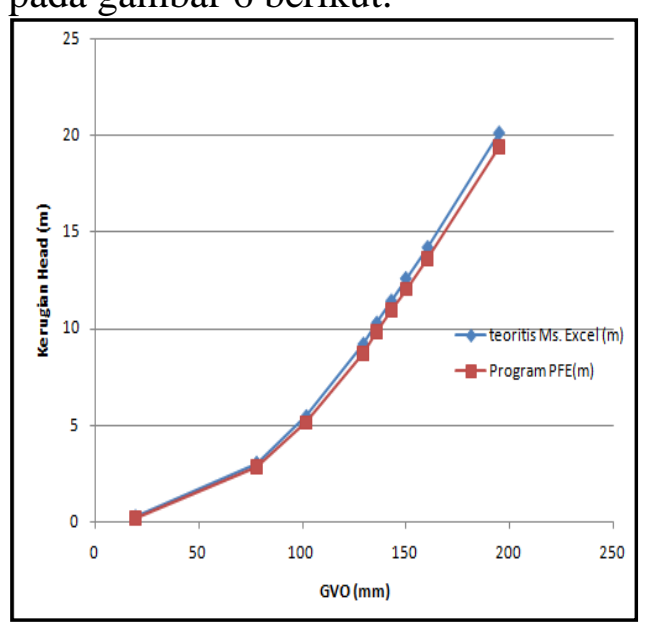

Gambar 6. Grafik hubungan Bukaan Sudu Pengarah terhadap kerugian Head Teoritis dan Program

Dari grafik diatas terlihat bahwa besarnya kerugian head total hasil simulasi software Pipe Flow Expert memiliki nilai yang sedikit lebih kecil daripada hasil perhitungan teoritis. Terdapat persen ralat yang paling kecil 3,84\% dan yang paling besar 7,60 \%. Penyumbang persen ralat paling besar yaitu pada kerugian head mayor.

\section{Daya Air (Water Horse Power)}

Adapun pengaruh bukaan sudu pengarah terhadap daya air dapat dilihat pada gambar 7 . 


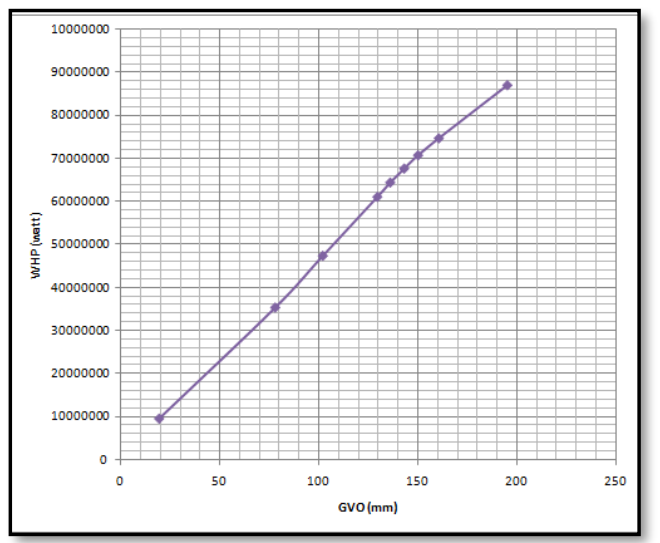

Gambar 7. Grafik Hubungan Bukaan Sudu Pengarah(GVO) dan Daya Air (WHP)

Dari grafik diatas terlihat bahwa besarnya daya air akan semakin besar seiring dengan semakin besarnya bukaan sudu pengarah Pada bukaan 19,5 mm daya air sebesar 9,5 MW terus naik hingga bukaan $195 \mathrm{~mm}$ mencapai $86 \mathrm{MW}$. Hal ini dikarenakan untuk menghitung daya air merupakan hasil perkalian antara daya, percepatan gravitasi, rapat jenis air dan head efektif yang bekerja.Debit air yang semakin besar akan berbanding terbalik dengan head efektif yang semakin kecil. Debit air yang begitu besar mempengaruhi besarnya daya air. Data daya air kemudian akan digunakan untuk menghitung efisiensi turbin francis vertikal.

\section{Daya Terbangkit}

Adapun pengaruh bukaan sudu pengarah terhadap daya air dapat dilihat pada gambar 8 .

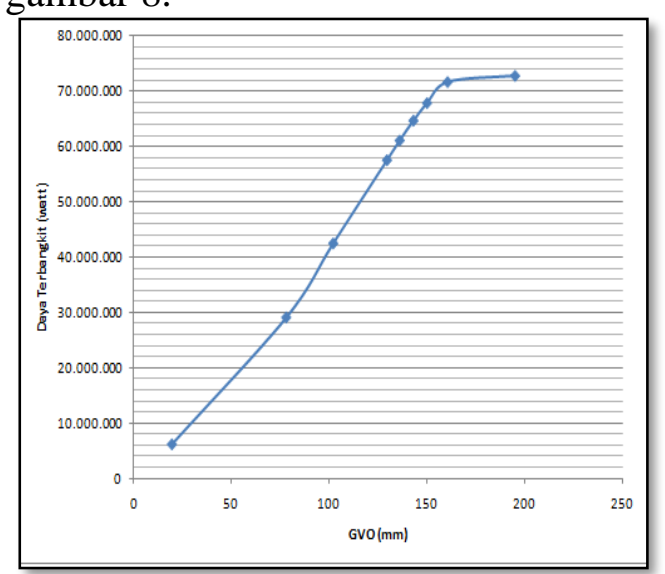

Gambar 8. Grafik Hubungan Bukaan Sudu Pengarah(GVO) dengan Daya Terbangkit

Data daya terbangkit hasil pembacaan Power Meter akan digunakan untuk menghitung daya turbin. Hal ini dikarenakan alat pembaca daya keluaran turbin tidak tersedia pada PT. Inalum. Jadi untuk menghitung digunakan data daya terbangkit dan efisiensi generator. Semakin besar bukaan sudu pengarah turbin francis maka daya terbangkit akan semakin besar.

Dari grafik diatas terlihat bahwa daya yang dibangkitkan oleh sistem mengalami nilai yang signifikan naik hingga bukaan 160,5 mm dan pada bukaan $195 \mathrm{~mm}$ mengalami kenaikan tetapi tidak terlalu signifikan. 


\section{Daya Turbin ( Brake Horse Power)}

Adapun pengaruh bukaan sudu pengarah terhadap daya turbin dapat dilihat pada gambar9.

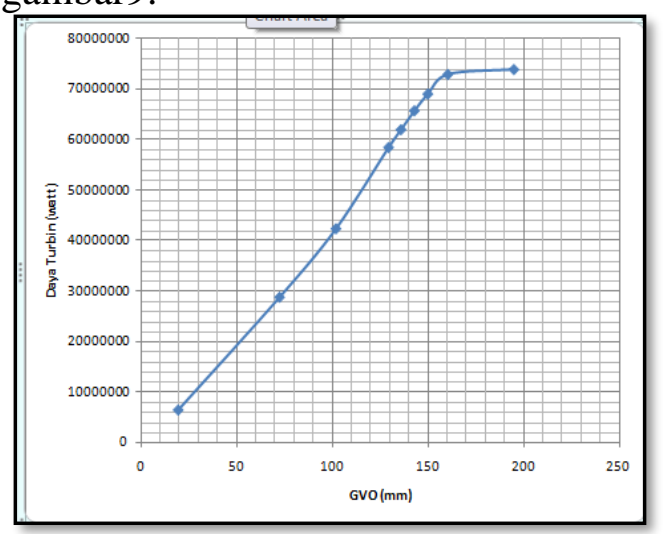

Gambar 9. Grafik Hubungan Bukaan Sudu Pengarah(GVO) dengan Daya Turbin

Dari grafik diatas terlihat bahwa Turbin menghasilkan daya paling kecil pada bukaan 19,5 mm yaitu sekitar 6,4 MW dan tertinggi pada bukaan $195 \mathrm{~mm}$ yaitu sekitar 78 MW. Daya yang dihasilkan oleh turbin mengalami kenaikan yang signifikan dari bukaan 19,5 mm hingga bukaan 160,5 mm dan pada bukaan $195 \mathrm{~mm}$ mengalami kenaikan tetapi tidak terlalu signifikan.

\section{Efisiensi Turbin}

Efisiensi akan terus naik seiring bukaan sudu pengarah akan tetapi pada bukaan $195 \mathrm{~mm}$ efisiensi turun pada titik 90,4 \%. Sehingga didapat bahwa bukaan sudu pengarah yang menghasilkan efisiensi maksimum yaitu pada bukaan 160, $5 \mathrm{~mm}$ yaitu sebesar $98 \%$. Pada bukaan maksimum $195 \mathrm{~mm}$ turbin akan mengalami penurunan efisiensi, hal ini dikarenakan turbin berputar terlalu cepat dari kecepatan turbin maksimal.

Hasil akhir dari penelitian ini yaitu efisiensi turbin francis vertikal seperti pada gambar 10 berikut.

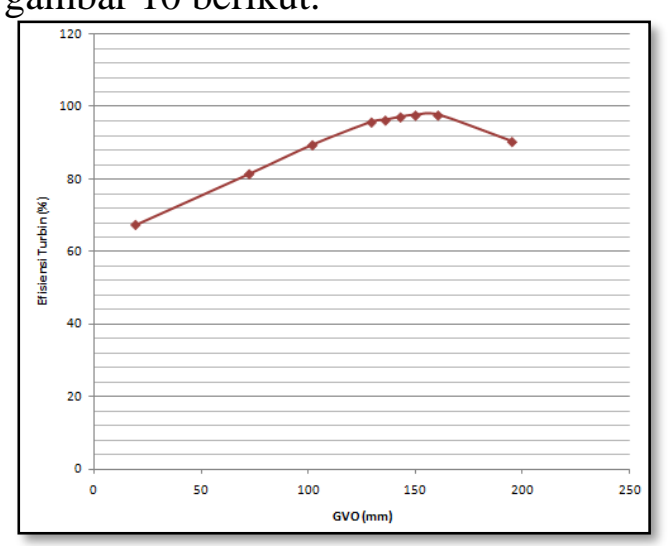

Gambar 10. Grafik Hubungan Bukaan Sudu Pengarah(GVO) dengan Efisiensi Turbin Francis Vertical

Besarnya efisiensi yang dihasilkan oleh turbin juga karena pengaruh kualitas dari komponen turbin tersebut. Besarnya nilai efisiensi turbin siguragura unit 3 salah satu faktor penyebabnya yaitu turbin pada Unit 3 PLTA Siguragura telah diganti baru (renewable/improvement) untuk meningkatkan efisiensi yaitu tepatnya pada tahun 2010 . 


\section{KESIMPULAN}

1. Pada Turbin Francis Vertikal semakin besar bukaan sudu pengarah maka akan berbanding lurus dengan besarnya kerugian head yang terjadi pada turbin tersebut. Pada bukaan terkecil yaitu $19,5 \mathrm{~mm}$ besarnya kerugian head yaitu 0,229 m kemudian akan terus naik hingga pada bukaan maksimum $195 \mathrm{~mm}$ besarnya kerugian head mencapai $20,1375 \mathrm{~m}$. Semakin besarnya kerugian head yang terdapat pada turbin ini diakibatkan oleh semakin besarnya debit air yang masuk turbin, juga karena semakin besarnya kecepatan aliran air di dalam instalasi turbin.

2. Pada simulasi program Pipe Flow Expert didapat nilai kerugian head terkecil yaitu pada bukaan 19,5 mm yaitu sebesar 0,212 $\mathrm{m}$ dan kemudian akan naik hingga bukaan maksimum $195 \mathrm{~mm}$ didapat besarnya kerugian head sebesar 19,365 m. Perbandingan hasil perhitungan kerugian minor teoritis dan simulasi didapat persen ralat yang sangat kecil sedangkan pada kerugian head mayor terdapat persen ralat yang cukup besar.

3. Daya turbin minimum dihasilkan pada bukaan $19,5 \mathrm{~mm}$ yaitu sebesar $6,4 \mathrm{MW}$ akan terus naik signifikan hingga bukaan 160,5 mm sebesar 73 MW akan tetapi pada bukaan $195 \mathrm{~mm}$ daya turbin tetap naik tetapi tidak signifikan yaitu hanya sebesar 78 MW. Hal ini disebabkan oleh semakin besarnya debit air masuk turbin juga oleh head efektif yang semakin kecil.Pada Turbin Francis Vertikal didapat efisiensi minimum terjadi pada bukaan $19,5 \mathrm{~mm}$ yaitu sebesar $67,4 \%$. Efisiensi akan terus naik seiring bukaan sudu pengarah akan tetapi pada bukaan $195 \mathrm{~mm}$ efisiensi turun pada titik 90,4 \%. Sehingga didapat bahwa bukaan sudu pengarah yang menghasilkan efisiensi maksimum yaitu pada bukaan $160,5 \mathrm{~mm}$ yaitu sebesar $98 \%$.

\section{DAFTAR PUSTAKA}

[1] Young, Hugh D. and friends. 2002. Fisika Universitas. Erlangga. Jakarta.

[2] Khurmi, R.S. Gupta, J.K. 1987. Mechanical Engineering (Conventional and Objective Type). S. Chand \& Company Limited. New Delhi.

[3] Shames, Irving H. 2005. Mechanic of Fluids..McGraw-Hill Companies. Singapore.

[4] Munson. Bruce R. and friends. 2006. Fundamentals Of Fluid Mechanics. John Wiley \& Sons (Asia) Pte Ltd. New Jersey.

[5] American Water Works Association.2004. Steel Pipe- A Guide for Design and Instalation. Denver USA.

[6] Rajput, R.K. 2007. Hydraulic Machines(Fluid Power Engineering). S. Chand \& Company Ltd. New Delhi.

[7] Marsudi, Djiteng. 2005. Pembangkitan Energi Listrik. Erlangga. Jakarta

[8] Dietzel, Fritz. 1996. Turbin, Pompa dan Kompresor. Erlangga. Jakarta.

[9] Dandeekar, M.M. 1979. Water Power Engineering. Vikas Publishing. Mumbai

[10] Agrawal, S.K. 1997. Fluid Mechanics and Machinery. Tata Mc. Graw Hill. New Delhi. 